\title{
ORIGINAL
}

\section{Bedside assessment of the effects of positive end-expiratory pressure on lung inflation and recruitment by the helium dilution technique and electrical impedance tomography}

\author{
Tommaso Mauri ${ }^{1}$, Nilde Eronia ${ }^{2}$, Cecilia Turrini ${ }^{1}$, Marta Battistini ${ }^{1}$, Giacomo Grasselli', Roberto Rona ${ }^{2}$,
} Carlo Alberto Volta ${ }^{3}$, Giacomo Bellani ${ }^{2,4}$ and Antonio Pesenti ${ }^{1,5^{*}}$ (i)

๑) 2016 Springer-Verlag Berlin Heidelberg and ESICM

\begin{abstract}
Purpose: Higher positive end-expiratory pressure might induce lung inflation and recruitment, yielding enhanced regional lung protection. We measured positive end-expiratory pressure-related lung volume changes by electrical impedance tomography and by the helium dilution technique. We also used electrical impedance tomography to assess the effects of positive end-expiratory pressure on regional determinants of ventilator-induced lung injury.

Methods: A prospective randomized crossover study was performed on 20 intubated adult patients: 12 with acute hypoxemic respiratory failure and 8 with acute respiratory distress syndrome. Each patient underwent protective controlled ventilation at lower $\left(7[7,8] \mathrm{cmH}_{2} \mathrm{O}\right)$ and higher $\left(12[12,13] \mathrm{cmH}_{2} \mathrm{O}\right)$ positive end-expiratory pressures. At the end of each phase, we collected ventilation, helium dilution, and electrical impedance tomography data.

Results: Positive end-expiratory pressure-induced changes in lung inflation and recruitment measured by electrical impedance tomography and helium dilution showed close correlations $\left(R^{2}=0.78, p<0.001\right.$ and $R^{2}=0.68, p<0.001$, respectively) but with relatively variable limits of agreement. At higher positive end-expiratory pressure, recruitment was evident in all lung regions $(p<0.01)$ and heterogeneity of tidal ventilation distribution was reduced by increased tidal volume distending the dependent lung $(p<0.001)$; in the non-dependent lung, on the other hand, compliance decreased $(p<0.001)$ and tidal hyperinflation significantly increased $(p<0.001)$. In the subgroup of ARDS patients (but not in the whole study population) tidal hyperinflation in the dependent lung regions decreased at higher positive end-expiratory pressure $(p=0.05)$, probably indicating higher potential for recruitment.
\end{abstract}

\footnotetext{
*Correspondence: antonio.pesenti@unimi.it

${ }^{1}$ Department of Anesthesia, Critical Care and Emergency, Fondazione IRCCS Ca' Granda Ospedale Maggiore Policlinico, Via F. Sforza 35, 20122 Milan, Italy

Full author information is available at the end of the article

Take-home message: Higher positive end-expiratory pressure induces changes in lung inflation, alveolar recruitment, and improvement (or worsening) of the main determinants of ventilator-induced lung injury. Combination of the helium dilution technique with electrical impedance tomography allows continuous assessment of PEEP effects at the bedside and could help personalized titration of mechanical ventilation.
} 
Conclusions: Close correlations exist between bedside assessment of positive end-expiratory pressure-induced changes in lung inflation and recruitment by the helium dilution and electrical impedance tomography techniques. Higher positive end-expiratory pressure exerts mixed effects on the regional determinants of ventilator-induced lung injury; these merit close monitoring.

Keywords: Acute respiratory distress syndrome, Mechanical ventilation, Positive end-expiratory pressure, Ventilatorinduced lung injury, Lung volume measurements, Electrical impedance

\section{Introduction}

Positive end-expiratory pressure (PEEP) is a key element of protective mechanical ventilation [1], being currently recommended for all intubated patients with acute hypoxemic respiratory failure and the acute respiratory distress syndrome (ARDS) [2]. PEEP was originally introduced after its ability to revert arterial hypoxemia [3], but, since then, several other physiological effects have been disclosed, both protective and deleterious for the lungs $[4,5]$. In fact, optimal setting of PEEP remains a topic of much controversy [2], and three large clinical trials showed no difference in the mortality of ARDS patients treated with lower vs. higher PEEP levels [6-8]. As personalized critical care medicine advances [9], the same applies to mechanical ventilation: physiologic studies as well as post hoc analysis of large trials showed that the assessment of specific effects of higher PEEP (e.g., improved oxygenation) on a per patient basis might better guide PEEP selection [10, 11]. To this end, optimal PEEP level should induce lung recruitment (which protects the lungs by decreasing stress and strain) [12] while avoiding worsening of the main determinants of ventilator-induced lung injury (VILI) (e.g., cyclic tidal hyperinflation) [13]. Thus, continuous bedside assessment of end-expiratory lung inflation, alveolar recruitment, and regional determinants of VILI at different PEEP levels might greatly enhance setting of personalized ventilation.

In this study, we compared bedside assessment of endexpiratory lung inflation and alveolar recruitment [14] by electrical impedance tomography (EIT), a non-invasive, radiation-free, dynamic lung imaging technique [15] with the helium dilution technique [16]. Indeed, at variance from the helium dilution technique, EIT yields continuous measures of lung volumes change, while, at variance from EIT, the helium dilution technique measures absolute values of end-expiratory lung volume (EELV). We reasoned that these techniques might represent a clinically useful combination for bedside advanced respiratory monitoring.

As secondary study objectives, we assessed by EIT the effects of higher PEEP on regional determinants of VILI such as tidal hyperinflation [17, 18], heterogeneity of tidal ventilation distribution [17], and the inhomogeneity of ventilation-perfusion matching. In particular, the last of these was estimated by EIT to quantify an oftenneglected cause of VILI: poor pairing of the regional ampleness of ventilation and perfusion that increases the risk of regional excessive minute ventilation and lung tissue alkalosis $[19,20]$. Tissue alkalosis, indeed, has been shown to cause alveolar cells necrosis, alveolar-epithelial barrier disruption, and edema [21].

In keeping with previous studies [17, 22, 23], we enrolled both intubated acute hypoxemic respiratory failure and ARDS patients, as alveolar collapse and derecruitment characterize both conditions $[17,24]$ and both populations benefit from application of lung protective ventilation strategies $[25,26]$.

This study has previously been presented at an international meeting and published as an abstract [27].

\section{Materials and methods Study population}

We conducted a prospective randomized crossover study on 20 intubated patients admitted to the general intensive care unit (ICU) of San Gerardo Hospital, Monza, Italy. Inclusion criteria were patients deeply sedated and paralyzed as per clinical decision; $\mathrm{PaO}_{2} / \mathrm{FiO}_{2} \leq 300 \mathrm{mmHg}$ with clinical positive end-expiratory pressure (PEEP) $\geq 5 \mathrm{cmH}_{2} \mathrm{O}$. Exclusion criteria were age $<18$ years, severe hemodynamic instability, evidence of cardiogenic pulmonary edema, history of chronic obstructive pulmonary disease, pregnancy, contraindications to the use of EIT (e.g., presence of pacemaker or automatic implantable cardioverter defibrillator), inability to place the EIT belt (e.g., presence of surgical wounds dressing). The ethical committee of San Gerardo Hospital, Monza, Italy approved the study and consent was obtained according to local regulations.

\section{Clinical data}

We collected sex, age, simplified acute physiology score II value at ICU admission, infectious vs. non-infectious and primary vs. extrapulmonary etiology of the acute respiratory failure, days of intubation, diagnosis of ARDS, and in-hospital mortality. Diagnosis of ARDS was based on the Berlin definition [28]: onset of the respiratory 
failure over 1 week or less; bilateral opacities consistent with pulmonary edema on CT scan or chest radiograph; $\mathrm{PaO}_{2} / \mathrm{FiO}_{2} \leq 300 \mathrm{mmHg}$ with a minimum of $5 \mathrm{cmH}_{2} \mathrm{O}$ PEEP; lung edema not fully explained by cardiac failure or fluid overload. Thus, in the present study, the only difference between patients with acute hypoxemic respiratory failure and ARDS was presence of unilateral vs. bilateral opacities.

\section{EIT monitoring}

We placed an EIT dedicated belt containing 16 electrodes around the patient's chest at the fifth or sixth intercostal space, and connected it to an EIT monitor (PulmoVista ${ }^{\circledR} 500$, Dräger Medical GmbH, Lübeck, Germany). EIT data were generated by application of small alternating electrical currents rotating around patient's thorax, continuously registered at $20 \mathrm{~Hz}$ during all study phases and stored for offline analysis, as previously described [17].

\section{Study protocol}

Patients were connected to a ventilator (Evita, Dräger Medical GmbH, Lübeck, Germany) and volume control ventilation was set as follows: tidal volume (Vt) $6-8 \mathrm{~mL} /$ $\mathrm{kg}$ of predicted body weight (PBW), clinical PEEP, $\mathrm{FiO}_{2}$ to obtain a $\mathrm{SpO}_{2}$ level $>90 \%$, and respiratory rate (RR) set to obtain arterial $\mathrm{pH}$ of 7.30-7.45. Patients were kept supine and the backrest of the bed was positioned at an angle $\geq 30^{\circ}$.

After checking for stability, we performed the study which consisted of two randomized crossover steps (i.e., all patients undergoing both phases) lasting 20 min each:

1. Clinical PEEP (PEEP $\left.{ }_{\text {low }}\right)$

2. Clinical PEEP $+5 \mathrm{cmH}_{2} \mathrm{O}\left(\mathrm{PEEP}_{\text {high }}\right)$

$\mathrm{Vt}, \mathrm{FiO}_{2}$, and $\mathrm{RR}$ were not modified and we did not set a maximum plateau pressure (Pplat) limit during the PEEP $_{\text {high }}$ step.

\section{Gas exchange, hemodynamics, ventilation, and helium dilution data}

During the last minutes of each phase, we assessed arterial blood gases and hemodynamics and we performed end-inspiratory and end-expiratory occlusions to measure Pplat, Vt, and total PEEP $\left(\right.$ PEEP $\left._{\text {tot }}\right)$. We also measured EELV by the simplified helium dilution technique, as previously described [16]. Measures of EELV by the helium dilution technique at each PEEP level were performed in triplicate and averaged. Then, from analysis of ventilation tracings during occlusions, we calculated the respiratory system static compliance $(\mathrm{Crs})$ as $\mathrm{Vt} /\left(\right.$ Pplat $\left._{-} \mathrm{PEEP}_{\text {tot }}\right)$. Finally, from helium dilution data, we calculated
1. Changes in the end-expiratory lung inflation at higher PEEP $\left(\triangle \mathrm{EELV}_{\mathrm{He}}\right)$, as the difference between the EELV measurements obtained at the two PEEP levels by helium dilution technique

2. Lung recruitment at higher PEEP $\left(\operatorname{RECR}_{\mathrm{He}}\right)$, as the increase in end-expiratory lung inflation measured by the helium dilution technique minus the change in end-expiratory inflation predicted from the respiratory system compliance measured at $\mathrm{PEEP}_{\text {low }}$ [i.e., $\operatorname{RECR}_{\mathrm{He}}=\Delta \mathrm{EELV}_{\mathrm{He}}-\Delta \mathrm{EELV}_{\mathrm{Crs}}=\Delta \mathrm{EELV}_{\mathrm{He}}$ - $\left.\left(\mathrm{PEEP}_{\text {low }} \mathrm{Crs} \times \triangle \mathrm{PEEP}\right)\right]$, as previously described $[14,29]$

\section{EIT data}

We horizontally split the EIT images into two contiguous regions of interests (ROI) of the same size: non-dependent from halfway up ( $\left.\mathrm{ROI}_{\text {non-dep }}\right)$ and dependent from halfway down $\left(\mathrm{ROI}_{\mathrm{dep}}\right)$. Then, from offline analyses of EIT data obtained during the last minutes of each study phase, we measured

1. Changes in end-expiratory lung inflation at higher PEEP $\left(\triangle \mathrm{EELV}_{\mathrm{EIT}}\right)$, as previously described [17]. Briefly, we measured change in end-expiratory lung impedance between the two PEEP levels and multiplied it by the ratio between Vt expressed in milliliters and the corresponding tidal impedance variation, both measured at PEEP ${ }_{\text {low }}$. Non-dependent and dependent $\triangle E E L V_{\text {EIT }}$ was also measured by the same method using regional end-expiratory impedance changes, tidal volumes, and tidal impedance variations [17].

2. Lung recruitment at higher PEEP measured across the whole imaging field $\left(\mathrm{RECR}_{\mathrm{EIT}}\right)$, as the increase in end-expiratory inflation measured by EIT minus the change in end-expiratory lung inflation predicted from the respiratory system compliance measured at $\mathrm{PEEP}_{\text {low }}$ [i.e., REC$\mathrm{R}_{\mathrm{EIT}}=\Delta \mathrm{EELV}_{\mathrm{EIT}}-\Delta \mathrm{EELV}_{\mathrm{Crs}}=\Delta \mathrm{EELV}_{\mathrm{EIT}}-(\mathrm{PEE}-$ $\mathrm{P}_{\text {low }}$ Crs $\left.\left.\times \triangle \mathrm{PEEP}\right)\right]$, as previously described [14, 29].

3 . The Vt distending non-dependent and dependent lung regions, $\left(\mathrm{Vt}_{\text {non-dep }}\right.$ and $\mathrm{Vt}_{\mathrm{dep}}$, respectively) (Fig. 1).

4. The heterogeneity of ventilation distribution, dynamically assessed along inspiration [i.e., intratidal ventilation heterogeneity $\left.\left(\mathrm{ITV}_{\mathrm{Het}}\right)\right]$, as previously described [17]. Briefly, we defined ITV $\mathrm{Het}_{\mathrm{Het}}$ as the average value of the $\mathrm{Vt}_{\text {non-dep }} / \mathrm{Vt}_{\text {dep }}$ ratios along inspiration when Vt was divided into eight equal-volume parts.

5. The heterogeneity of tidal ventilation distribution at end inspiration $\left(\mathrm{Vt}_{\mathrm{Het}}\right)$, defined as the $\mathrm{Vt} \mathrm{t}_{\text {non-dep }} / \mathrm{Vt}_{\text {dep }}$ ratio [10]. 

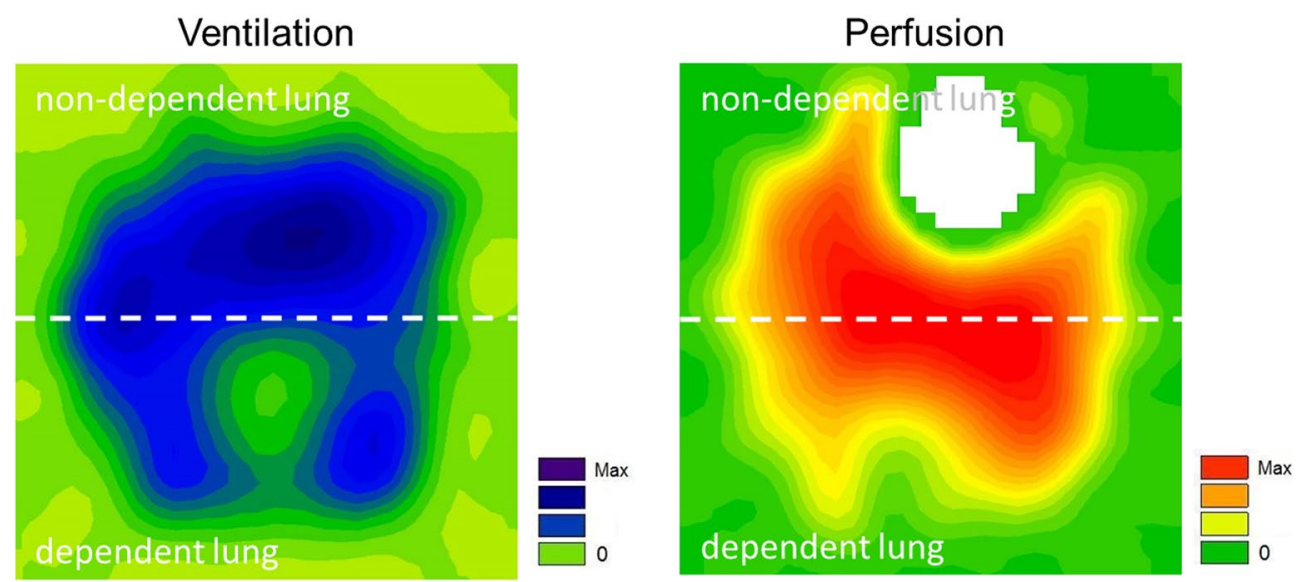

Fig. 1 Lung ventilation and perfusion assessed by electrical impedance tomography. Examples of regional distribution of the ampleness of pulmonary ventilation (left) and perfusion (right) measured by electrical impedance tomography in one representative study patient. Electrical impedance tomography continuously measures regional impedance changes within the thorax by injection of alternating micro-currents spinning around a belt of multiple electrodes positioned at the fifth or sixth intercostal space. When a low-pass filter is applied to raw electrical impedance tomography data with the upper limit set above the patient's respiratory rate and below the heart rate, impedance changes correspond to changes in chest gas content. In this way, regional distribution of tidal ventilation in gravitationally dependent and non-dependent lung regions can be monitored (green no ventilation, light blue to purple scalar representation of ventilated pixels). Instead, when a band-pass filter is applied with the lower limit set above the respiratory rate and higher limit above the heart rate, impedance changes typically show two peak values, corresponding to heart filling and to lung perfusion respectively (Video 1 online). In this study, pixels with maximal activity during the first peak were visually recognized and removed from the imaging field as pertaining to the heart (white area in the upper part of the right image), while pixel-level impedance changes measured at the second peak within the newly generated imaging field were regarded as pixel-level lung perfusion (green non-perfused pixels, yellow to red scalar representation of perfused pixels)

6. The regional $\mathrm{Crs}$ values, measured as $\mathrm{Vt}_{\text {non-dep }}$ or $\mathrm{Vt}_{\mathrm{dep}}$ divided by the difference between end-inspiratory Pplat and PEEP $\mathrm{P}_{\text {tot }}\left(\mathrm{Crs}_{\text {non-dep }}\right.$ and $\mathrm{Crs}_{\text {dep }}$, respectively) [17]. Decreased $\mathrm{Crs}_{\text {non-dep }}$ at $\mathrm{PEEP}_{\text {high }}$ might indicate increased risk of regional tidal hyperinflation while increased $\mathrm{Crs}_{\text {dep }}$ might correlate with regional recruitment.

7. Lung recruitment at higher PEEP in non-dependent and dependent lung regions $\left(\mathrm{RECR}_{\mathrm{EIT}}\right.$ non-dep and RECR $_{\text {EIT }}$ dep) as the regional increase of $\triangle E E L V_{\text {EIT }}$ minus the change in end-expiratory inflation in the same area predicted from regional respiratory system compliances measured at $\mathrm{PEEP}_{\text {low }}$ [i.e., REC$\mathrm{R}_{\text {EIT }}$ non-dep $=\Delta \mathrm{EELV}_{\mathrm{EIT}}$ non-dep $-\left(\mathrm{PEEP}_{\text {low- }}\right.$ $\left.\mathrm{Crs}_{\text {non-dep }} \times \triangle \mathrm{PEEP}\right)$ and $\mathrm{RECR}_{\text {EIT }}$ dep $=\triangle \mathrm{EELV}_{\mathrm{EIT}}$ dep - $\left.\left(\mathrm{PEEP}_{\text {low }} \mathrm{Crs}_{\text {dep }} \times \triangle \mathrm{PEEP}\right)\right][14,29]$.

8. Tidal hyperinflation at each PEEP level, as previously described $[17,18]$. Briefly, the pixel-level tidal hyperinflation was calculated as

Tidal hyperinflation pixel $(\%)$

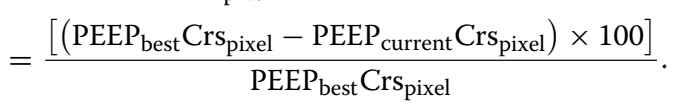

$\mathrm{PEEP}_{\text {best }}$ indicating the level associated with the highest pixel-level Crs. Then, cumulated tidal hyperinflation for the whole imaging field (1024 pixels) was computed as

Tidal hyperinflation (\%)

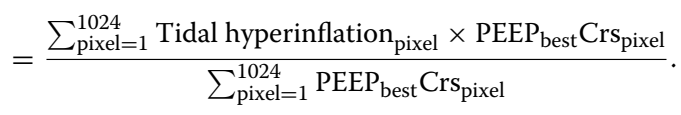

Regional values of tidal hyperinflation were obtained by the same formulas considering only the pixels included in $\mathrm{ROI}_{\text {non-dep }}$ and $\mathrm{ROI}_{\mathrm{dep}}$.

9. We exploited a new index of the regional homogeneity of ventilation-perfusion matching $\left(\mathrm{V} / \mathrm{P}_{\mathrm{Hom}}\right)$, corresponding to the $R^{2}$ coefficient of the linear regression constructed by plotting the pixel-level impedance changes related to ventilation against the pixel-level impedance changes related to lung perfusion, both assessed by EIT (Fig. 1). Briefly, pixel-level lung perfusion was measured by EIT as the cyclic impedance change related to cardiac activity within the lungs: after application of band-pass filtering to raw EIT data (i.e., lower limit set above respiratory rate and higher limit above heart rate), heart-related impedance changes correspond to the first peak of global impedance change, while lung perfusion corresponds to the second peak (Video 1 in the online data supplement). 
Thus, to calculate $\mathrm{V} / \mathrm{P}_{\mathrm{Hom}}$, pixels with maximal activity during the first peak were visually recognized and removed from the imaging field as pertaining to the heart [30], while pixel-level impedance changes measured at the second peak within the newly generated imaging field were regarded as pixel-level lung perfusion (Fig. 1 and Video 1 online).

\section{Statistical analysis}

Sample size was chosen to detect an $R^{2}$ correlation coefficient between $\triangle$ EELV measured by EIT and helium technique of at least 0.6 with power of 0.8 and alpha 0.05 . Comparisons between two groups of normally distributed variables were performed by repeated measure $t$ test, while non-normally distributed variables were compared by Wilcoxon signed rank test. Normality was tested by the Shapiro-Wilk test. Association between two variables was assessed by linear regression. Agreement between measures of $\triangle E E L V$ and recruitment assessed by helium dilution technique and EIT was analyzed by Bland-Altman and standardized residuals plots. Moreover, the intraclass correlation coefficient (ICC), which provides a scalar measure of concordance between the two methods, was calculated: the value 1 represents perfect agreement, and 0 as no agreement at all. A level of $p<0.05$ (two-tailed) was considered as statistically significant. Normally distributed data are indicated as mean \pm standard deviation, while median and interquartile range are used to report non-normally distributed variables. Statistical analyses were performed by SigmaPlot 11.0 (Systat Software Inc., San Jose, CA, USA).

\section{Results}

\section{Patients' characteristics}

Patients' characteristics are listed in Table 1. Patients were $62 \pm 12$ years old and $8(40 \%)$ were women. Etiology of respiratory failure was infectious in 13 patients (65\%) and primary in nine patients (45\%). All patients were enrolled early in the course of the disease within 1 week from intubation. In seven patients $(35 \%) \mathrm{PaO}_{2} /$ $\mathrm{FiO}_{2}$ values were between 200 and $300 \mathrm{mmHg}$ while all other 13 patients $(65 \%)$ presented $\mathrm{PaO}_{2} / \mathrm{FiO}_{2}$ values between 100 and $200 \mathrm{mmHg}$. Eight patients (40 \%) fulfilled the Berlin definition of ARDS (Table 1) and seven patients ( $35 \%)$ died during their hospital stay.

\section{Assessment of changes in end-expiratory lung inflation and recruitment induced by PEEP by helium and EIT}

As expected, increasing PEEP from $7[7,8] \mathrm{cmH}_{2} \mathrm{O}$ to $12[12,13] \mathrm{cmH}_{2} \mathrm{O}(p<0.001)$ (Table 2) significantly increased absolute values of end-expiratory lung inflation, as assessed by the helium dilution technique
$(2038 \pm 636$ vs. $1551 \pm 556 \mathrm{~mL}, p<0.001)$. Bedside measures of the changes in lung inflation assessed by helium $\left(\triangle \mathrm{EELV}_{\mathrm{He}}\right)$ and by EIT $\left(\triangle \mathrm{EELV}_{\mathrm{EIT}}\right)$ disclosed very similar values $(486 \pm 193$ vs. $460 \pm 177 \mathrm{~mL}, p=0.66)$ (Table 2) and the correlation between $\triangle \mathrm{EELV}_{\mathrm{He}}$ and $\Delta \mathrm{EELV}_{\mathrm{EIT}}$ was highly significant $\left(R^{2}=0.78, p<0.001\right)$ (Fig. 2a). Moreover, ICC between measures of $\triangle E E L V_{\mathrm{He}}$ and $\triangle E E L V_{\text {EIT }}$ was 0.867 , indicating very good agreement. To further exploit the correlation between the two methods, we calculated Bland-Altman analysis (Fig. 2b) that revealed mean difference of $-3 \pm 98 \mathrm{~mL}$ and limits of agreement between -190 and $189 \mathrm{~mL}$, which indicates some variability. Similarly, when we assessed lung recruitment by subtraction of the measured values of $\triangle E E L V_{\mathrm{He}}$ and $\triangle E E L V_{\mathrm{EIT}}$ minus the expected value of $\triangle$ EELV $_{\text {Crs }}$ calculated as $\left(\mathrm{PEEP}_{\text {low }} \mathrm{Crs} \times \triangle \mathrm{PEEP}\right)$, the two techniques disclosed highly correlated results (linear regression: $R^{2}=0.68, p<0.001$; ICC $=0.812$ ) (Table 2; Fig. 2d) and relatively variable limits of agreement (mean difference $-26 \mathrm{~mL}$, limits of agreement -211 to $160 \mathrm{~mL}$ ) (Fig. 2e). Higher PEEP induced regional recruitment assessed by EIT both in non-dependent and dependent lung (Table 3), with the non-dependent regions showing non-significantly higher values $(p=0.257)$.

\section{Effects of higher PEEP levels on regional determinants of VILI}

As in previous studies, increasing PEEP induced significant redistribution of tidal volume from non-dependent towards dependent lung regions. Indeed, at $\mathrm{PEEP}_{\text {high, }}$, the tidal volume reaching ventral non-dependent lung ( $\mathrm{Vt}_{\text {non- }}$ dep $)$ significantly decreased $(p<0.001)$ and tidal ventilation of the dependent region $\left(\mathrm{Vt}_{\mathrm{dep}}\right)$ increased $(p<0.001)$ (Table 3). As a consequence, higher PEEP level decreased heterogeneity of tidal ventilation distribution measured along inspiration ( $\left.\mathrm{ITV}_{\mathrm{Het}}, p<0.001\right)$ and at the end of it $\left(\mathrm{Vt}_{\mathrm{Het}}, p<0.001\right)$ (Table 3; Fig. 3a).

However, at higher PEEP, compliance of the nondependent lung regions decreased and EIT-based values of tidal hyperinflation increased in the same region $\left(p<0.001\right.$ vs. PEEP ${ }_{\text {low }}$ for both) (Table 3; Fig. 3c, d). Tidal hyperinflation induced by higher PEEP was confirmed also by increased $\mathrm{PaCO}_{2}$ values in the presence of unchanged minute ventilation (Table 2), likely indicating increased dead space. Interestingly, tidal hyperinflation was significantly higher at $\mathrm{PEEP}_{\text {high }}$ even in the presence of mean plateau pressure largely within recommended protective limits (Table 2). The compliance of the dependent dorsal lung did not change significantly $(p=0.14$, Table 3$)$ suggesting marginal recruitment and, as regional $\mathrm{Vt}_{\text {dep }}$ increased (Table 3 ), this might have led to increased regional transpulmonary pressure and lung stress. 
Table 1 Main characteristics of the study population

\begin{tabular}{|c|c|c|c|c|c|c|c|c|c|}
\hline Patient no. & Sex & Age (years) & $\begin{array}{l}\text { SAPS II at ICU } \\
\text { admission }\end{array}$ & Etiology & $\begin{array}{l}\text { Days from intu- } \\
\text { bation }\end{array}$ & $\begin{array}{l}\text { Diagnosis } \\
\text { of ARDS }\end{array}$ & $\begin{array}{l}\text { Clinical } \\
\text { PEEP } \\
\left(\mathrm{cmH}_{2} \mathrm{O}\right)\end{array}$ & $\begin{array}{l}\mathrm{PaO}_{2} / \mathrm{FiO}_{2} \text { at } \\
\text { clinical PEEP } \\
(\mathrm{mmHg})\end{array}$ & $\begin{array}{l}\text { In-hospital } \\
\text { mortality }\end{array}$ \\
\hline 1 & M & 58 & 45 & $\begin{array}{l}\text { Primary, infec- } \\
\text { tious }\end{array}$ & 1 & Y & 7 & 168 & $\mathrm{~N}$ \\
\hline 2 & M & 62 & 66 & $\begin{array}{c}\text { Extrapulmo- } \\
\text { nary, non- } \\
\text { infectious }\end{array}$ & 1 & $\mathrm{~N}$ & 5 & 196 & Y \\
\hline 3 & M & 54 & 45 & $\begin{array}{c}\text { Extrapulmo- } \\
\text { nary, non- } \\
\text { infectious }\end{array}$ & 2 & $\mathrm{~N}$ & 7 & 230 & Y \\
\hline 4 & $\mathrm{~F}$ & 72 & 42 & $\begin{array}{l}\text { Extrapul- } \\
\text { monary, } \\
\text { infectious }\end{array}$ & 1 & Y & 8 & 166 & $\mathrm{~N}$ \\
\hline 5 & M & 58 & 23 & $\begin{array}{l}\text { Primary, non- } \\
\text { infectious }\end{array}$ & 1 & $\mathrm{~N}$ & 5 & 279 & $\mathrm{~N}$ \\
\hline 6 & $\mathrm{~F}$ & 65 & 41 & $\begin{array}{l}\text { Extrapul- } \\
\text { monary, } \\
\text { infectious }\end{array}$ & 1 & Y & 8 & 171 & $\mathrm{~N}$ \\
\hline 7 & M & 68 & 50 & $\begin{array}{l}\text { Primary, infec- } \\
\text { tious }\end{array}$ & 2 & Y & 8 & 140 & Y \\
\hline 8 & M & 86 & 81 & $\begin{array}{c}\text { Extrapulmo- } \\
\text { nary, non- } \\
\text { infectious }\end{array}$ & 1 & $\mathrm{~N}$ & 5 & 290 & Y \\
\hline 9 & $\mathrm{~F}$ & 66 & 59 & $\begin{array}{l}\text { Extrapul- } \\
\text { monary, } \\
\text { infectious }\end{array}$ & 6 & Y & 10 & 190 & Y \\
\hline 10 & $\mathrm{~F}$ & 74 & 65 & $\begin{array}{l}\text { Extrapul- } \\
\text { monary, } \\
\text { infectious }\end{array}$ & 5 & $\mathrm{~N}$ & 7 & 172 & Y \\
\hline 11 & M & 76 & 67 & $\begin{array}{l}\text { Primary, infec- } \\
\text { tious }\end{array}$ & 1 & $\mathrm{~N}$ & 7 & 136 & N \\
\hline 12 & M & 70 & 56 & $\begin{array}{l}\text { Extrapul- } \\
\text { monary, } \\
\text { infectious }\end{array}$ & 2 & $\mathrm{~N}$ & 8 & 219 & N \\
\hline 13 & $\mathrm{~F}$ & 76 & 50 & $\begin{array}{c}\text { Extrapulmo- } \\
\text { nary, non- } \\
\text { infectious }\end{array}$ & 1 & Y & 9 & 139 & Y \\
\hline 14 & M & 45 & 58 & $\begin{array}{l}\text { Primary, infec- } \\
\text { tious }\end{array}$ & 1 & N & 7 & 190 & $\mathrm{~N}$ \\
\hline 15 & $\mathrm{~F}$ & 67 & 27 & $\begin{array}{c}\text { Extrapulmo- } \\
\text { nary, non- } \\
\text { infectious }\end{array}$ & 1 & $\mathrm{~N}$ & 7 & 260 & $\mathrm{~N}$ \\
\hline 16 & M & 50 & 39 & $\begin{array}{l}\text { Primary, infec- } \\
\text { tious }\end{array}$ & 1 & Y & 5 & 290 & $\mathrm{~N}$ \\
\hline 17 & $\mathrm{~F}$ & 38 & 33 & $\begin{array}{l}\text { Primary, infec- } \\
\text { tious }\end{array}$ & 1 & $\mathrm{~N}$ & 8 & 284 & $\mathrm{~N}$ \\
\hline 18 & $\mathrm{~F}$ & 40 & 45 & $\begin{array}{l}\text { Primary, infec- } \\
\text { tious }\end{array}$ & 1 & $\mathrm{~N}$ & 8 & 188 & N \\
\hline 19 & M & 58 & 27 & $\begin{array}{c}\text { Extrapulmo- } \\
\text { nary, non- } \\
\text { infectious }\end{array}$ & 1 & $\mathrm{~N}$ & 7 & 153 & $\mathrm{~N}$ \\
\hline 20 & M & 55 & 35 & $\begin{array}{l}\text { Primary, infec- } \\
\text { tious }\end{array}$ & 5 & Y & 10 & 105 & $N$ \\
\hline Mean \pm SD & $8 \mathrm{~F} / 12 \mathrm{M}$ & $62 \pm 12$ & $48 \pm 15$ & $\begin{array}{l}9 \text { primary/11 } \\
\text { extrapul- } \\
\text { monary, } 13 \\
\text { infectious/7 } \\
\text { non-infec- } \\
\text { tious }\end{array}$ & $2 \pm 1$ & $8 \mathrm{Y} / 12 \mathrm{~N}$ & $7 \pm 1$ & $199 \pm 57$ & $7 \mathrm{Y} / 13 \mathrm{~N}$ \\
\hline
\end{tabular}

SAPS // simplified acute physiology score II, ICU intensive care unit, $A R D S$ acute respiratory distress syndrome, $P E E P$ positive end-expiratory pressure, $P a O_{2} /$ FiO ${ }_{2}$ oxygen partial arterial tension/inspired oxygen fraction 
Table 2 Ventilation, lung inflation, and recruitment at lower and higher PEEP

\begin{tabular}{|c|c|c|c|}
\hline Variable & PEEP $_{\text {low }}$ & PEEP $_{\text {high }}$ & $p$ value $^{*}$ \\
\hline PEEP $\left(\mathrm{cmH}_{2} \mathrm{O}\right)$ & $7(7-8)$ & $12(12-13)$ & $<0.001$ \\
\hline $\mathrm{PaO}_{2} / \mathrm{FiO}_{2}(\mathrm{mmHg})$ & $199 \pm 57$ & $203 \pm 60$ & 0.54 \\
\hline $\mathrm{FiO}_{2}$ & $0.50(0.45-0.55)$ & $0.50(0.45-0.55)$ & 1.00 \\
\hline Vt (mL/Kg PBW) & $7.0(6.0-7.3)$ & $6.8(6.0-7.2)$ & 0.94 \\
\hline $\mathrm{Vt}(\mathrm{mL})$ & $462(367-496)$ & $462(364-498)$ & 0.94 \\
\hline $\mathrm{RR}$ (bpm) & $18(16-23)$ & $18(16-23)$ & 1.00 \\
\hline MVe (L/min) & $8.1(6.5-9.9)$ & $8.2(6.6-9.7)$ & 0.72 \\
\hline $\mathrm{P}_{\text {plat }}\left(\mathrm{cmH}_{2} \mathrm{O}\right)$ & $16(14-19)$ & $22(19-25)$ & $<0.001$ \\
\hline $\mathrm{PaCO}_{2}(\mathrm{mmHg})$ & $42 \pm 5$ & $44 \pm 4$ & $<0.01$ \\
\hline$\Delta \mathrm{EELV}_{\mathrm{He}}(\mathrm{mL})$ & Baseline & $486 \pm 193$ & $<0.001$ \\
\hline$\Delta \mathrm{EELV}_{\mathrm{EIT}}(\mathrm{mL})$ & Baseline & $460 \pm 177$ & $<0.001$ \\
\hline $\mathrm{RECR}_{\mathrm{He}}(\mathrm{mL})$ & Baseline & $227 \pm 166$ & $<0.001$ \\
\hline $\operatorname{RECR}_{E I T}(\mathrm{~mL})$ & Baseline & $202 \pm 144$ & $<0.001$ \\
\hline
\end{tabular}

Data are expressed as mean \pm standard deviation for normally distributed variables and as median (interquartile range) for non-normally distributed ones PEEP positive end-expiratory pressure, $\mathrm{PaO}_{2} / \mathrm{FiO}_{2}$ oxygen partial arterial tension/ inspired oxygen fraction, $V t$ tidal volume, $P B W$ predicted body weight, $R R$ respiratory rate, $M V$ e expired minute ventilation, $P_{\text {plat }}$ plateau pressure, $\mathrm{PaCO}_{2}$ carbon dioxide partial arterial pressure, $\triangle E E L V_{H_{e}}$ change of end-expiratory lung volume at $\mathrm{PEEP}_{\text {high }}$ measured by helium dilution technique, $\triangle E E L V_{E I T}$ change of end-expiratory lung volume measured by electrical impedance tomography, $R E C R_{H e}$ lung recruitment assessed by helium dilution technique, $R E C R_{E I T}$ lung recruitment assessed by electrical impedance tomography

* $p$ value by paired $t$ test or by Wilcoxon signed rank test, as appropriate

Finally, at higher PEEP level, homogeneity of the ventilation-perfusion matching assessed in the whole imaging field (i.e., $\mathrm{V} / \mathrm{P}_{\text {Hom }}$ ) significantly improved in comparison to $\operatorname{PEEP}_{\text {low }}(p<0.05)$ (Fig. 3b; Table 3). In particular, by regional analysis, improved homogeneity of ventilationperfusion matching induced by higher PEEP was more relevant in the non-dependent lung (Table 3).

\section{Differences between acute hypoxemic respiratory failure and ARDS patients}

Interestingly, in the correlations as well as in the BlandAltman and standardized residuals plots of $\triangle E E L V$ and recruitment, we could not identify any systematic bias for acute hypoxemic respiratory failure vs. ARDS patients (Fig. 2c, f). Considering only the subgroup of ARDS patients ( $n=8$, Tables 1 and 2 online), at variance from the whole study population, at higher PEEP $\mathrm{PaCO}_{2}$ increase was not significant $(p=0.131)$, global Crs values decreased non-significantly $(p=0.204)$, and tidal hyperinflation in the dependent lung regions decreased $(p=0.05)$. Study results, instead, did not differ in the subgroup of acute respiratory failure patients with unilateral lung infiltrates ( $n=12$, data not shown) vs. the whole population. Thus, with the limits of the small sample size, we might hypothesize that, at higher PEEP levels, the risk of non-dependent tidal hyperinflation and increased dorsal stress was lower in the ARDS subgroup, maybe indicating more potential for recruitment (expected in diffuse bilateral vs. unilateral patterns [31]).

\section{Discussion}

Study main findings are (1) in intubated acute hypoxemic respiratory failure and ARDS patients, EIT may represent an accurate method to continuously monitor changes in end-expiratory lung inflation and recruitment at the bedside and a valuable addition to punctual measure of absolute EELV by helium dilution technique; (2) higher PEEP might increase lung protection by inducing recruitment across all lung regions and improving homogeneity of ventilation distribution and of ventilation-perfusion matching; (3) at the same time, higher PEEP might increase the risk of cyclic tidal hyperinflation in the non-dependent lung regions and of elevated stress in the dependent ones even at relatively low plateau pressure.

VILI is a severe complication of mechanical ventilation, adding further morbidity and mortality to the underlying acute lung condition [32]. In recent years, attention was drawn to increased lung strain (i.e., the Vt/EELV ratio) as key determinant of VILI [33-35]. In fact, higher regional strain is associated with increased inflammation and lung edema [33-35]. When PEEP is increased, lung inflation increases both by re-aeration of partially or completely collapsed alveolar units (i.e., recruitment) or by additional gas volume added to previously open lung [29]. If recruitment represents a significant amount of the change in lung aeration, higher PEEP might be regarded as relatively reducing strain, potentially granting enhanced lung protection [12]. Thus, tracking end-expiratory inflation changes and recruitment at the bedside might represent a valuable method to identify optimal PEEP setting. In this study, we compared an EIT-based method to measure changes in end-expiratory lung inflation and recruitment with the helium dilution technique [16], showing tight correlations but relative variability in the limits of agreement. However, helium dilution technique showed relatively large limits of agreement with chest CT scan [16], probably because it can only measure EELV in lung regions accessible to ventilation. EIT, instead, can measure EELV changes also in non-ventilated lung regions and the variability that we reported might reflect tighter rather than looser agreement between chest EIT and CT scan. Although both helium dilution technique and EIT have limits (see below), our data might suggest that, knowing the tidal volume, helium dilution technique could allow bedside monitoring of lung inflation and strain at a given PEEP level; then, EIT could track inflation, strain, and recruitment in a continuous fashion at varying PEEP levels [36]. 

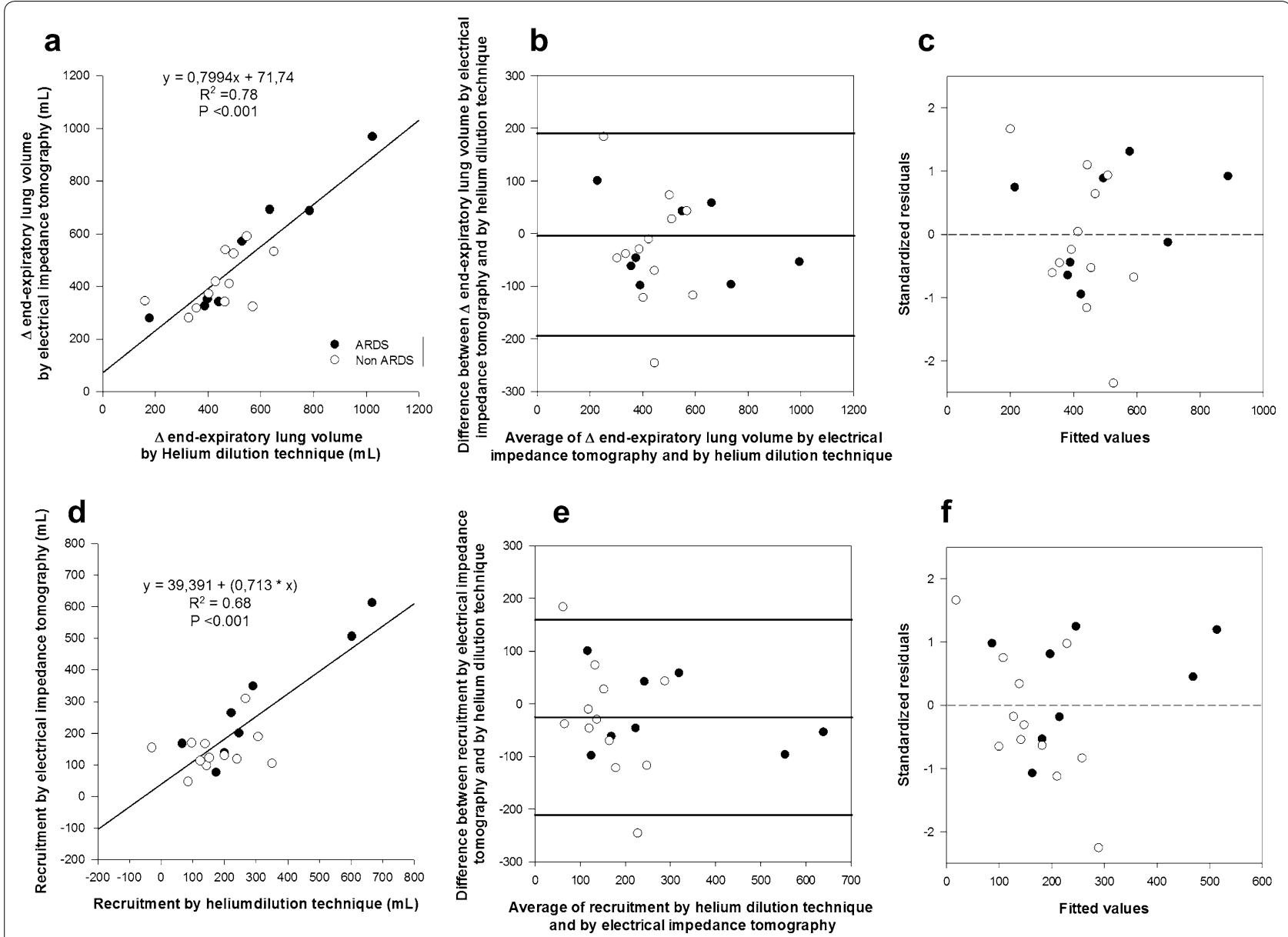

Fig. 2 Comparison between helium dilution technique and electrical impedance tomography: end-expiratory lung inflation and recruitment. Top panels correlation between changes in end-expiratory lung volume ( $\triangle E E L V)$ assessed by electrical impedance tomography (EIT) and by the helium dilution technique (a) in 20 acute hypoxemic respiratory failure and ARDS patients; Bland-Altman plot $\mathbf{b}$ showing limits of agreement between the two measures and c standardized residuals plot apparently showing no evident systematic bias. Lower panels: linear regression (d), Bland-Altman plot (e), and standardized residuals plot (f) of lung recruitment (RECR) assessed by electrical impedance tomography (EIT) and by helium dilution technique. In this study, recruitment was defined as re-aeration of partially or totally collapsed lung units at higher PEEP and measured by subtracting expected changes of end-expiratory lung inflation based on respiratory system compliance measured at PEEP low from actual changes assessed by the two techniques (see text for details)

Pathogenesis of VILI is multifactorial, and, other than strain, the following mechanisms might play a (more or less neglected) role: (1) increased regional transpulmonary pressures and lung stress [37]; (2) multiplication of the lung distending forces by regional inhomogeneities [38]; (3) cells apoptosis and necrosis induced by regional tissue hypocapnic alkalosis secondary to excessive minute ventilation [19-21]; (4) regional tidal hyperinflation causing direct mechanical disruption of cells' membrane and inflammation [13]. In this study, higher PEEP level (around $12 \mathrm{cmH}_{2} \mathrm{O}$ ) seemed to impact the aforementioned VILI mechanisms in comparison to lower PEEP (ca. $7 \mathrm{cmH}_{2} \mathrm{O}$ ) both in positive and detrimental directions. On the one hand, higher PEEP increases the homogeneity of ventilation and, as the extent of lung inhomogeneities is inversely related to regional ventilation homogeneity [39], our data generates the hypothesis that higher PEEP might enhance regional lung protection by decreasing the presence of regional inhomogeneities and stress raisers [38]. Moreover, the homogeneity of lung ventilation-perfusion matching was improved at higher PEEP, especially in the non-dependent lung, which might seem counterintuitive. However, in this study, recruitment (which should enhance ventilation-perfusion matching [40]) tended to be more represented in the non-dependent lung regions and redirection of tidal ventilation to the dependent lung might have increased ventilation-perfusion homogeneity by limiting excessive minute ventilation in the nondependent regions. We might hypothesize that, at higher PEEP, the risk of regional hypocapnic alkalosis and its 
Table 3 Regional effects of higher PEEP on the determinants of ventilation-induced lung injury

\begin{tabular}{|c|c|c|c|}
\hline Variable & $\mathrm{PEEP}_{\text {low }}$ & PEEP $_{\text {high }}$ & $p$ value $^{*}$ \\
\hline $\mathrm{RECR}_{\mathrm{EIT}}$ non-dep (mL) & Baseline & $145 \pm 95$ & $<0.01$ \\
\hline $\mathrm{RECR}_{\mathrm{EIT}} \operatorname{dep}(\mathrm{mL})$ & Baseline & $61 \pm 68$ & $<0.001$ \\
\hline$V t_{\text {non-dep }}(m L)$ & $305 \pm 77$ & $284 \pm 76$ & $<0.001$ \\
\hline $\mathrm{Vt}_{\text {dep }}(\mathrm{mL})$ & $132 \pm 38$ & $150 \pm 38$ & $<0.001$ \\
\hline ITV $_{\text {Het }}$ & $2.3(2.1-2.9)$ & $1.8(1.7-2.6)$ & $<0.001$ \\
\hline $\mathrm{Vt}_{\text {Het }}$ & $2.2(1.8-2.7)$ & $1.8(1.4-2.5)$ & $<0.001$ \\
\hline $\operatorname{Crs}\left(\mathrm{mL} / \mathrm{cmH}_{2} \mathrm{O}\right)$ & $52 \pm 15$ & $48 \pm 15$ & $<0.001$ \\
\hline $\mathrm{Crs}_{\text {non-dep }}\left(\mathrm{mL} / \mathrm{CmH}_{2} \mathrm{O}\right)$ & $37 \pm 13$ & $31 \pm 12$ & $<0.001$ \\
\hline $\mathrm{Crs}_{\text {dep }}\left(\mathrm{mL} / \mathrm{cmH}_{2} \mathrm{O}\right)$ & $15 \pm 5$ & $16 \pm 5$ & 0.14 \\
\hline Tidal hyperinflation (\%) & $5.9 \pm 4.0$ & $17.4 \pm 5.9$ & $<0.001$ \\
\hline Tidal hyperinflation non-dep $(\%)$ & $2.8 \pm 2.7$ & $20.6 \pm 6.8$ & $<0.001$ \\
\hline Tidal hyperinflation dep $(\%)$ & $12.9 \pm 10.2$ & $10.7 \pm 6.3$ & 0.49 \\
\hline V/P & $0.34 \pm 0.22$ & $0.42 \pm 0.22$ & $<0.05$ \\
\hline V/P Hom non-dep & $0.43 \pm 0.23$ & $0.54 \pm 0.22$ & $<0.001$ \\
\hline V/P Hom dep & $0.31 \pm 0.23$ & $0.34 \pm 0.28$ & 0.57 \\
\hline
\end{tabular}

Data are expressed as mean \pm standard deviation for normally distributed variables and as median (interquartile range) for non-normally distributed ones

$R E C R_{E I T}$ lung recruitment assessed by electrical impedance tomography, non-dep non-dependent lung regions, dep dependent lung regions, $V t$ tidal volume, $I T V_{\text {Het }}$ intratidal ventilation distribution heterogeneity index, $V t_{H e t}$ ventilation distribution heterogeneity index at the end of inspiration, $C r$ respiratory system compliance, $V / P_{\text {Hom }}$ ventilation/perfusion homogeneity index

* $p$ value by paired $t$ test or by Wilcoxon signed rank test, as appropriate

detrimental effects on non-dependent alveoli might be reduced [19-21]. On the other hand, higher PEEP worsened mechanics of the non-dependent lung, likely by increasing end-expiratory lung inflation and shifting the regional respiratory system closer to total lung capacity and to the right unfavorable part of its pressure-volume curve [41]. As a consequence, cyclic tidal hyperinflation increased in the same region, even at apparently "safe" plateau pressure, and the stiffer non-dependent regions forcefully redistributed Vt towards the dependent ones. However, the dorsal recruitment obtained by this shift was relatively small, $\mathrm{Crs}_{\text {dep }}$ did not change significantly, and this likely led to increased transpulmonary pressure in the dependent lung. Thus, at higher PEEP, both the non-dependent lung (through higher tidal hyperinflation) and the dependent one (through higher stress) might be at increased risk of mechanical injury to alveolar cells and structures $[13,37]$. Our data seem to suggest that, rather than finding an universal strategy for PEEP setting, accurate respiratory monitoring to detect the most appropriate PEEP level for each patient (e.g., the one obtaining reduced lung strain with improvement and/or minimal worsening of the main determinants of VILI) could be the key for selection of optimal PEEP level.

In this study, higher PEEP was not associated with improved oxygenation, even in the presence of alveolar recruitment and improved homogeneity of ventilationperfusion matching. However, PEEP affects oxygenation by mechanisms different from recruitment [29]; moreover, the index we developed only indicates more homogeneous coupling of the regional ampleness of ventilation and perfusion, while the total amount of perfusion reaching non-ventilated zones (i.e., pulmonary shunt-one of the main determinants of hypoxemia) might have remained unchanged.

Our study has several limitations. (1) The sample size is relatively small; however, we continuously recorded a variety of physiological tracings and parameters, allowing accurate assessment of the pathophysiological pattern of each patient. (2) Study phases were relatively short but we hypothesized that its length was enough to obtain stable physiological measures $[10,17]$. (3) We enrolled both acute hypoxemic respiratory failure and ARDS patients, which might have introduced some heterogeneity; however, studying the effects of higher PEEP on lung strain seems clinically relevant for both conditions [25, 26]. (4) EIT measures only a portion of the lungs, corresponding roughly to half of their size; however, on the basis of the present and previous data, this seems a clinically acceptable compromise [15]. Moreover, both EIT and helium dilution technique have relatively low resolution, but we reasoned that the advantage of being bedside, radiation-less, and continuous greatly enhances their clinical validity and translation. (5) We did not measure the potential for lung recruitment at very high airway pressures, for which no EIT-based approach was validated, but we rather chose to study inflation and recruitment at PEEP values that are more commonly used in clinical practice [42]. (6) We did not use two prespecified protocols to set lower vs. higher PEEP, but rather compared clinical vs. clinical $+5 \mathrm{cmH}_{2} \mathrm{O}$ PEEP (which might be regarded as a real-life PEEP test). We decided to implement this pragmatic design because we wanted to test the helium dilution technique and EIT in real life and achieve maximum external validity. (7) The method we used to quantify recruitment assumes linear behavior of the respiratory system compliance between the two PEEP levels and was originally validated measuring EELV change by the nitrogen washinwashout method [14] (which has previously been shown to correlate with EIT measures of lung volume changes [36]).

In conclusion, in intubated acute hypoxemic respiratory failure and ARDS patients, combination of helium dilution technique and EIT may allow continuous bedside monitoring of the absolute values of lung inflation and recruitment and of the main determinants of VILI. To this end, higher PEEP might be associated with recruitment of non-dependent and dependent lung regions, decreased ventilation heterogeneity, and increased homogeneity of regional ventilation-perfusion matching, all of which might be regarded as potentially reducing the risk 

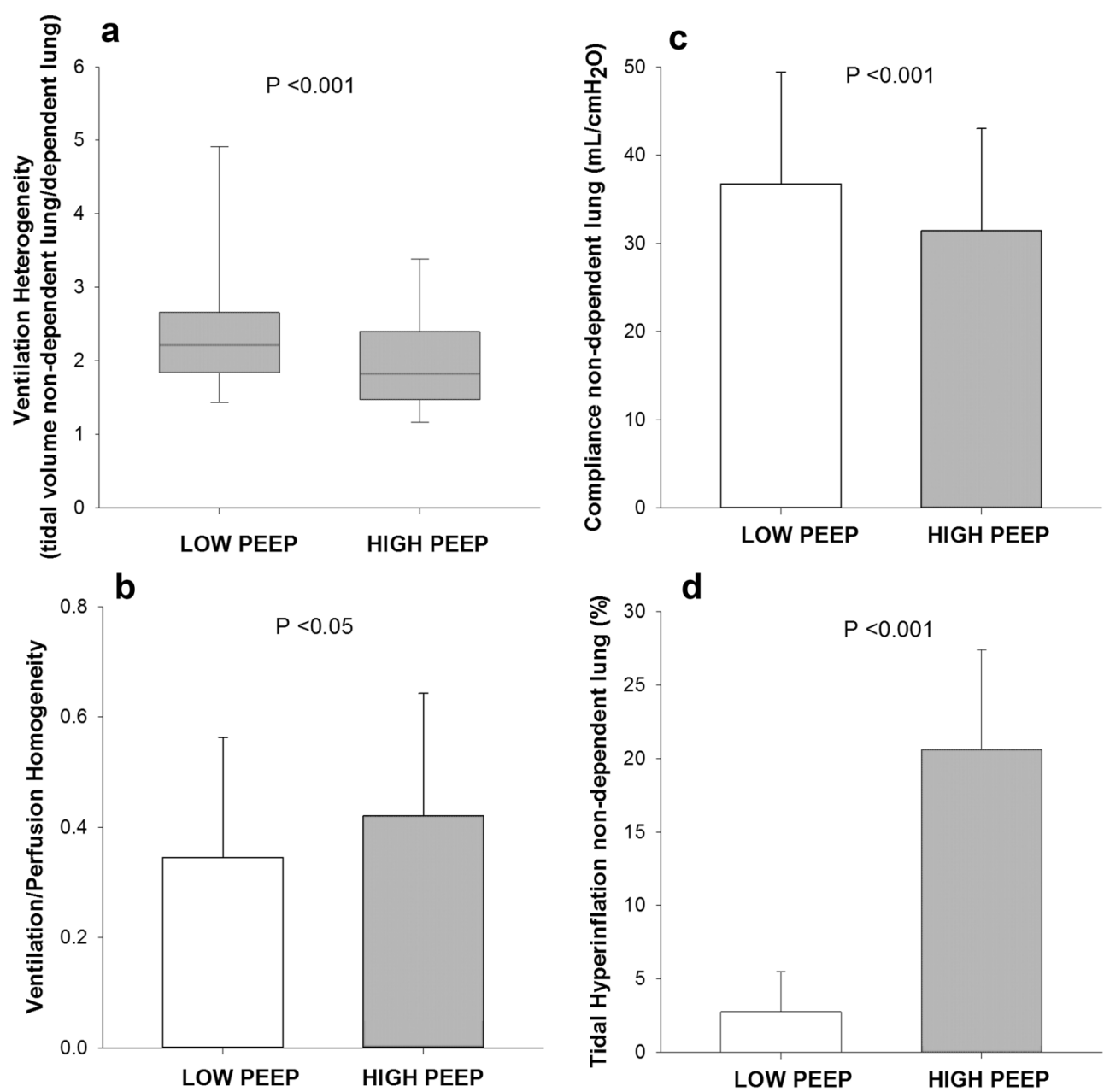

Fig. 3 Effects of higher PEEP on the determinants of ventilator-induced lung injury. Higher PEEP induced mixed effects on regional determinants of ventilator-induced lung injury: in fact, heterogeneity of ventilation distribution $\left(\mathrm{Vt}_{\mathrm{dep}} / \mathrm{Vt}\right.$ non-dep $)$ was reduced (a) and homogeneity of ventilation-perfusion distribution $\left(\mathrm{V}^{\mathrm{P}} \mathrm{P}_{\mathrm{Hom}}\right)$ improved $(\mathbf{b})$ suggesting lung protection, while compliance of non-dependent regions (Crs $\left.\mathrm{Con}_{\text {-dep }}\right)$ and tidal hyperinflation of the non-dependent lung worsened $(\mathbf{c}, \mathbf{d})$ indicating higher risk of barotrauma. See text for detailed methods used to quantify these variables

of VILI. Contemporarily, higher PEEP seems to increase tidal hyperinflation of the non-dependent lung regions and increase tidal stress in the dependent ones, thus increasing the risk of VILI. Careful bedside assessment of the effects of PEEP on lung inflation, recruitment, and regional determinants of VILI might be essential for personalized PEEP titration and to fully exploit the beneficial effects of PEEP on patient outcome.

\section{Electronic supplementary materia}

The online version of this article (doi:10.1007/s00134-016-4467-4) contains supplementary material, which is available to authorized users.

\section{Author details}

${ }^{1}$ Department of Anesthesia, Critical Care and Emergency, Fondazione IRCCS Ca'Granda Ospedale Maggiore Policlinico, Via F. Sforza 35, 20122 Milan, Italy. ${ }^{2}$ Department of Emergency, San Gerardo Hospital, Monza, Italy. ${ }^{3}$ Department of Morphology, Surgery and Experimental Medicine, Section of Anesthesia and Intensive Care, University of Ferrara, Ferrara, Italy. ${ }^{4}$ Department of Medicine and Surgery, University of Milan-Bicocca, Monza, Italy. ${ }^{5}$ Department of Pathophysiology and Transplantation, University of Milan, Milan, Italy.

\section{Acknowledgments}

The present study was supported by departmental funding.

\section{Compliance with ethical standards}

\section{Conflicts of interest}

The authors have no conflict of interest to declare.

Received: 27 April 2016 Accepted: 28 July 2016

Published online: 12 August 2016

\section{References}

1. Dreyfuss D, Soler P, Basset G, Saumon G (1988) High inflation pressure pulmonary edema. Respective effects of high airway pressure, high 
tidal volume, and positive end-expiratory pressure. Am Rev Respir Dis 137(5):1159-1164

2. Gattinoni L, Carlesso E, Cressoni M (2015) Selecting the'right' positive end-expiratory pressure level. Curr Opin Crit Care 21(1):50-57

3. Ashbaugh DG, Bigelow DB, Petty TL, Levine BE (1967) Acute respiratory distress in adults. Lancet 2(7511):319-323

4. Yoshida T, Roldan R, Beraldo MA, Torsani V, Gomes S, De Santis RR, Costa EL, Tucci MR, Lima RG, Kavanagh BP, Amato MB (2016) Spontaneous effort during mechanical ventilation: maximal injury with less positive endexpiratory pressure. Crit Care Med. doi:10.1097/CCM.0000000000001649

5. Retamal J, Bugedo G, Larsson A, Bruhn A (2015) High PEEP levels are associated with overdistension and tidal recruitment/derecruitment in ARDS patients. Acta Anaesthesiol Scand 59(9):1161-1169

6. The National Heart Lung, and Blood Institute ARDS Clinical Trials Network (2004) Higher versus lower positive end-expiratory pressures in patients with the acute respiratory distress syndrome. N Engl J Med 351:327-336

7. Mercat A, Richard JC, Vielle B, Jaber S, Osman D, Diehl JL, Lefrant JY, Prat G, Richecoeur J, Nieszkowska A, Gervais C, Baudot J, Bouadma L, Brochard L, Expiratory Pressure (Express) Study Group (2008) Positive end-expiratory pressure setting in adults with acute lung injury and acute respiratory distress syndrome: a randomized controlled trial. JAMA 299(6):646-655

8. Meade MO, Cook DJ, Guyatt GH, Slutsky AS, Arabi YM, Cooper DJ, Davies AR, Hand LE, Zhou Q, Thabane L, Austin P, Lapinsky S, Baxter A, Russell J, Skrobik Y, Ronco JJ, Stewart TE, Lung Open Ventilation Study Investigators (2008) Ventilation strategy using low tidal volumes, recruitment maneuvers, and high positive end-expiratory pressure for acute lung injury and acute respiratory distress syndrome: a randomized controlled trial. JAMA 299(6):637-645

9. Beitler JR, Goligher EC, Schmidt M, Spieth PM, Zanella A, Martin-Loeches I, Calfee CS, Cavalcanti AB, ARDSne(x)t Investigators (2016) Personalized medicine for ARDS: the 2035 research agenda. Intensive Care Med 42(5):756-767

10. Mauri T, Bellani G, Confalonieri A, Tagliabue P, Turella M, Coppadoro A, Citerio G, Patroniti N, Pesenti A (2013) Topographic distribution of tidal ventilation in acute respiratory distress syndrome: effects of positive endexpiratory pressure and pressure support. Crit Care Med 41(7):1664-1673

11. Goligher EC, Kavanagh BP, Rubenfeld GD, Adhikari NK, Pinto R, Fan E, Brochard LJ, Granton JT, Mercat A, Marie Richard JC, Chretien JM, Jones GL, Cook DJ, Stewart TE, Slutsky AS, Meade MO, Ferguson ND (2014) Oxygenation response to positive end-expiratory pressure predicts mortality in acute respiratory distress syndrome. A secondary analysis of the LOVS and ExPress trials. Am J Respir Crit Care Med 190(1):70-76

12. Chiumello D, Cressoni M, Carlesso E, Caspani ML, Marino A, Gallazzi E, Caironi P, Lazzerini M, Moerer O, Quintel M, Gattinoni L (2014) Bedside selection of positive end-expiratory pressure in mild, moderate, and severe acute respiratory distress syndrome. Crit Care Med 42(2):252-264

13. Terragni PP, Rosboch G, Tealdi A, Corno E, Menaldo E, Davini O, Gandini G, Herrmann P, Mascia L, Quintel M, Slutsky AS, Gattinoni L, Ranieri VM (2007) Tidal hyperinflation during low tidal volume ventilation in acute respiratory distress syndrome. Am J Respir Crit Care Med 175(2):160-166

14. Dellamonica J, Lerolle N, Sargentini C, Beduneau G, Di Marco F, Mercat A, Richard JC, Diehl JL, Mancebo J, Rouby JJ, Lu Q, Bernardin G, Brochard L (2011) PEEP-induced changes in lung volume in acute respiratory distress syndrome. Two methods to estimate alveolar recruitment. Intensive Care Med 37(10):1595-1604

15. van der Burg PS, Miedema M, de Jongh FH, Frerichs I, van Kaam AH (2014) Cross-sectional changes in lung volume measured by electrical impedance tomography are representative for the whole lung in ventilated preterm infants. Crit Care Med 42(6):1524-1530

16. Patroniti N, Bellani G, Manfio A, Maggioni E, Giuffrida A, Foti G, Pesenti A (2004) Lung volume in mechanically ventilated patients: measurement by simplified helium dilution compared to quantitative $C T$ scan. Intensive Care Med 30(2):282-289

17. Mauri T, Eronia N, Abbruzzese C, Marcolin R, Coppadoro A, Spadaro S, Patroniti N, Bellani G, Pesenti A (2015) Effects of sigh on regional lung strain and ventilation heterogeneity in acute respiratory failure patients undergoing assisted mechanical ventilation. Crit Care Med 43(9):1823-1831

18. Costa EL, Borges JB, Melo A, Suarez-Sipmann F, Toufen C Jr, Bohm SH, Amato MB (2009) Bedside estimation of recruitable alveolar collapse and hyperdistension by electrical impedance tomography. Intensive Care Med 35(6):1132-1137
19. Kolobow T, Spragg RG, Pierce JE (1981) Massive pulmonary infarction during total cardiopulmonary bypass in unanesthetized spontaneously breathing lambs. Int J Artif Organs 4(2):76-81

20. Edmunds $\mathrm{LH}$, Holm JC (1969) Effect of inhaled $\mathrm{CO}_{2}$ on hemorrhagic consolidation due to unilateral pulmonary arterial ligation. J Appl Physiol 26(6):710-715

21. Ando T, Mikawa K, Nishina K, Misumi T, Obara H (2007) Hypocapnic alkalosis enhances oxidant-induced apoptosis of human alveolar epithelial type II cells. J Int Med Res 35(1):1 18-126

22. Blankman P, Shono A, Hermans BJ, Wesselius T, Hasan D, Gommers D (2016) Detection of optimal PEEP for equal distribution of tidal volume by volumetric capnography and electrical impedance tomography during decreasing levels of PEEP in post cardiac-surgery patients. Br J Anaesth 116(6):862-869

23. Constantin JM, Futier E, Cherprenet AL, Chanques G, Guerin R, CayotConstantin S, Jabaudon M, Perbet S, Chartier C, Jung B, Guelon D, Jaber S, Bazin JE (2010) A recruitment maneuver increases oxygenation after intubation of hypoxemic intensive care unit patients: a randomized controlled study. Crit Care 14(2):R76

24. Gattinoni L, Pelosi P, Vitale G, Pesenti A, D'Andrea L, Mascheroni D (1991) Body position changes redistribute lung computed-tomographic density in patients with acute respiratory failure. Anesthesiology 74(1):15-23

25. Serpa Neto A, Simonis FD, Barbas CS, Biehl M, Determann RM, Elmer J, Friedman G, Gajic O, Goldstein JN, Horn J, Juffermans NP, Linko R, de Oliveira RP, Sundar S, Talmor D, Wolthuis EK, de Abreu MG, Pelosi P, Schultz MJ (2014) Association between tidal volume size, duration of ventilation, and sedation needs in patients without acute respiratory distress syndrome: an individual patient data meta-analysis. Intensive Care Med 40(7):950-957

26. The Acute Respiratory Distress Syndrome Network (2000) Ventilation with lower tidal volumes as compared with traditional tidal volumes for acute lung injury and the acute respiratory distress syndrome. N Engl I Med 342(18):1301-1308

27. Mauri T, Eronia N, Turrini Cambiaghi BC, Benini A, Bellani G, Pesenti A (2015) Effects of positive end expiratory pressure on regional ventilationperfusion matching and respiratory mechanics: a clinical study. Intensive Care Med Exp 3(S1):A8

28. ARDS Definition Task Force, Ranieri VM, Rubenfeld GD, Thompson BT, Ferguson ND, Caldwell E, Fan E, Camporota L, Slutsky AS (2012) Acute respiratory distress syndrome: the Berlin definition. JAMA 307(23):2526-2533

29. Chiumello D, Marino A, Brioni M, Cigada I, Menga F, Colombo A, Crimella F, Algieri I, Cressoni M, Carlesso E, Gattinoni L (2015) Lung recruitment assessed by respiratory mechanics and by CT scan: what is the relationship? Am J Respir Crit Care Med 193(11):1254-1263

30. Becher T, Vogt B, Kott M, Schädler D, Weiler N, Frerichs I (2016) Functional regions of interest in electrical impedance tomography: a secondary analysis of two clinical studies. PLOS One 11(3):e0152267

31. Constantin JM, Grasso S, Chanques G, Aufort S, Futier E, Sebbane M, Jung B, Gallix B, Bazin JE, Rouby JJ, Jaber S (2010) Lung morphology predicts response to recruitment maneuver in patients with acute respiratory distress syndrome. Crit Care Med 38:1108-1117

32. Hussein O, Walters B, Stroetz R, Valencia P, McCall D, Hubmayr RD (2013) Biophysical determinants of alveolar epithelial plasma membrane wounding associated with mechanical ventilation. Am J Physiol Lung Cell Mol Physiol 305(7):L478-L484

33. Bellani G, Guerra L, Musch G, Zanella A, Patroniti N, Mauri T, Messa C, Pesenti A (2011) Lung regional metabolic activity and gas volume changes induced by tidal ventilation in patients with acute lung injury. Am J Respir Crit Care Med 183(9):1193-1199

34. Gattinoni L, Marini JJ, Pesenti A, Quintel M, Mancebo J, Brochard L (2016) The "baby lung" became an adult. Intensive Care Med 42(5):663-673

35. Protti A, Cressoni M, Santini A, Langer T, Mietto C, Febres D, Chierichetti M, Coppola S, Conte G, Gatti S, Leopardi O, Masson S, Lombardi L, Lazzerini M, Rampoldi E, Cadringher P, Gattinoni L (2011) Lung stress and strain during mechanical ventilation: any safe threshold? Am J Respir Crit Care Med 183(10):1354-1362

36. Hinz J, Hahn G, Neumann P, Sydow M, Mohrenweiser P, Hellige G, Burchardi $\mathrm{H}$ (2003) End-expiratory lung impedance change enables bedside monitoring of end-expiratory lung volume change. Intensive Care Med 29(1):37-43 
37. Protti A, Andreis DT, Monti M, Santini A, Sparacino CC, Langer T, Votta E, Gatti S, Lombardi L, Leopardi O, Masson S, Cressoni M, Gattinoni L (2013) Lung stress and strain during mechanical ventilation: any difference between statics and dynamics? Crit Care Med 41(4):1046-1055

38. Pesenti A, Musch G, Lichtenstein D, Mojoli F, Amato MB, Cinnella G, Gattinoni L, Quintel M (2016) Imaging in acute respiratory distress syndrome. Intensive Care Med 42(5):686-698

39. Mertens M, Tabuchi A, Meissner S, Krueger A, Schirrmann K, Kertzscher U, Pries AR, Slutsky AS, Koch E, Kuebler WM (2009) Alveolar dynamics in acute lung injury: heterogeneous distension rather than cyclic opening and collapse. Crit Care Med 37(9):2604-2611

40. Tusman G, Suarez-Sipmann F, Bohm SH, Borges JB, Hedenstierna G (2011) Capnography reflects ventilation/perfusion distribution in a model of acute lung injury. Acta Anaesthesiol Scand 55(5):597-606
41. Pelosi P, Goldner M, McKibben A, Adams A, Eccher G, Caironi P, Losappio S, Gattinoni L, Marini JJ (2001) Recruitment and derecruitment during acute respiratory failure: an experimental study. Am J Respir Crit Care Med 164(1):122-130

42. Bellani G, Laffey JG, Pham T, Fan E, Brochard L, Esteban A, Gattinoni L, van Haren F, Larsson A, McAuley DF, Ranieri M, Rubenfeld G, Thompson BT, Wrigge H, Slutsky AS, Pesenti A, LUNG SAFE Investigators, ESICM Trials Group (2016) Epidemiology, patterns of care, and mortality for patients with acute respiratory distress syndrome in intensive care units in 50 countries. JAMA 315(8):788-800 